\title{
EDITORIAL PRINGIPLES
}

I have aimed to produce, as nearly as possible, a completely accurate diplomatic transcription. Punctuation has not been modernized and all abbreviations have been indicated by italics. Per and par are expanded according to modern spelling, mainly because Starkey never gave the words containing these contractions in full. In all other cases, abbreviations are spelled according to Starkey's usage; e.g. 'sprual' becomes 'sprytual'. 'I' and ' $\mathrm{j}$ ' have been modernized, and both have been rendered lower case except in the first person pronoun and a few proper names. ' $U$ ' and ' $v$ ' have also been modernized. Otherwise the only detail I have deliberately ignored is Starkey's almost constant alteration of 'Le' into 'Lupset'. Because of the vagaries of Starkey's spelling and numerous apparent errors of transcription, including missing words, I have avoided [sic]. I have occasionally supplied single letters in the interests of avoiding pedantry, usually when a mecron is likely to have faded beyond legibility. Two or three of Starkey's idiosyncracies may cause some confusion, especially the interchangeable use of 'the' and 'they', and the peculiar treatment of terminal 'gh', which led him to write 'strenghth', for example, and drop a final ' $t$ ' after those letters in many cases. Transposed characters have not been corrected, but words broken at the end of lines have been silently joined. Likewise, I have not distinguished between marginal and interlinear insertions, in part because Starkey was in the habit of beginning an insertion between lines and continuing it into the margin. Starkey's Latin is given as he wrote it, but his Greek has been rendered in current spelling because he wrote some characters no longer in use. 